\title{
Interim estimates of 2013/14 influenza clinical severity and vaccine effectiveness in the prevention of laboratory-confirmed influenza-related hospitalisation, Canada, February 2014
}

S A McNeil (shelly.mcneil@cdha.nshealth.ca) ${ }^{1}$, V Shinde ${ }^{2}$, M Andrew ${ }^{1}$, T F Hatchette ${ }^{1}$, J Leblanc ${ }^{1}$, A Ambrose L $^{1}$, G Boivin 3 , W R Bowie $^{4}$, F Diaz-Mitoma ${ }^{5}$, M ElSherif ${ }^{1}$, K Green ${ }^{6}$, F Haguinet ${ }^{2}$, S Halperin ${ }^{1}$, B Ibarguchi ${ }^{7}, K_{\text {Katz }}^{8}$, JM Langley ${ }^{1}$, P Lagacé-Wiens' B Light $^{9}$, M Loeb ${ }^{10}$, J McElhaney ${ }^{5}$, D MacKinnon-Cameron ${ }^{1}$, A E McCarthy ${ }^{11}$, M Poirier ${ }^{12}$, J Powis ${ }^{13}$, D Richardson ${ }^{14}$, M Semret ${ }^{15}$, S Smith $^{16}$, D Smyth ${ }^{17}$, G Stiver ${ }^{4}$, S Trottier ${ }^{3}$, L Valiquette ${ }^{18}$, D Webster ${ }^{19}$, L Ye $^{1}$, A McGeer ${ }^{6}$, on behalf of the Public Health Agency of Canada/Canadian Institutes of Health Research Influenza Research Network (PCIRN) Serious Outcomes Surveillance Network ${ }^{20}$, on behalf of the Toronto Invasive Bacterial Diseases Network (TIBDN) ${ }^{21}$

1. Canadian Center for Vaccinology, IWK Health Centre and Capital Health, Dalhousie University, Halifax, Nova Scotia, Canada

2. GlaxoSmithKline Biologicals, Wavre, Belgium

3. CHU de Québec, Quebec, Canada

4. University of British Columbia, Vancouver, British Columbia, Canada

5. Advanced Medical Research Institute of Canada, Sudbury, Ontario, Canada

6. Mount Sinai Hospital, Toronto, Ontario, Canada

7. GlaxoSmithKline, Mississauga, Ontario, Canada

8. North York General Hospital, Toronto, Ontario, Canada

9. St. Boniface Hospital, Winnipeg, Manitoba, Canada

10. McMaster University, Hamilton, Ontario, Canada

11. The Ottawa Hospital, Ottawa, Ontario, Canada

12. Centre de santé et de service sociaux de Trois-Rivieres, Trois-Rivieres, Quebec, Canada

13. Toronto East General Hospital, Toronto, Ontario, C

14. William Osler Health Centre, Brampton, Ontario, Canada

15. McGill University, Montreal, Quebec, Canada

16. University of Alberta, Edmonton, Alberta, Canada

17. The Moncton Hospital, Moncton, New Brunswick, Canada

18. Université de Sherbrooke, Sherbrooke, Quebec, Canada

19. Horizon Health, Saint John, New Brunswick, Canada

20. www.pcirn.ca

21. www.tibdn.ca

Citation style for this article:

McNeil SA, Shinde V, Andrew M, Hatchette TF, Leblanc J, Ambrose A, Boivin G, Bowie WR, Diaz-Mitoma F, ElSherif M, Green K, Haguinet F, Halperin S, Ibarguchi B Katz K, Langley J, Lagacé-Wiens P, Light B, Loeb M, McElhaney J, MacKinnon-Cameron D, McCarthy AE, Poirier M, Powis J, Richardson D, Semret M, Smith S, Smyth D, Stiver G, Trottier S, Valiquette L, Webster D, Ye L, McGeer A, on behalf of the Public Health Agency of Canada/Canadian Institutes of Health Research Influenza Research Network (PCIRN) Serious Outcomes Surveillance Network, on behalf of the Toronto Invasive Bacterial Diseases Network (TIBDN). Interim estimates of $2013 / 14$ influenza clinical severity and vaccine effectiveness in the prevention of laboratory-confirmed influenza-related hospitalisation, Canada, February 2014. Euro Surveill. 2014;19(9):pii=20729. Available online: http://www.eurosurveillance.org/ViewArticle.aspx?Articleld=20729

Article submitted on 24 February 2014 / published on 06 March 2014

During the 2013/14 influenza season in Canada, 631 of 654 hospitalisations for laboratory-confirmed influenza enrolled in sentinel hospitals were due to Influenza A. Of the 375 with known subtype, influenza $A\left(H_{1} N_{1}\right)$ accounted for 357 . Interim unmatched vaccine effectiveness adjusted for age and presence of one or more medical comorbidities was determined by testnegative case-control design to be $58.5 \%$ (90\% confidence interval $(\mathrm{Cl})$ : $43.9-69.3 \%$ ) overall and $57.9 \%$ ( $90 \% \mathrm{Cl}: 37 \cdot 7-71.5)$ for confirmed influenza $A\left(\mathrm{H}_{1} \mathrm{~N}_{1}\right)$.

In the context of the first influenza season in Canada since the 2009 influenza pandemic to be marked by the predominant circulation of $A\left(\mathrm{H}_{1} \mathrm{~N}_{1}\right)$ pdmog virus, we provide a critical interim assessment of overall and age-stratified 2013/14 influenza vaccine effectiveness against laboratory-confirmed influenza-associated hospitalisation. We describe the clinical and epidemiological characteristics of severe cases of influenza, defined as those requiring intensive care unit (ICU) admission, mechanical ventilation or resulting in death, who were hospitalised up to 8 February 2014 in the hospitals of the Public Health Agency of Canada/ Canadian Institutes of Health Research (PCIRN) Serious Outcomes Surveillance (SOS) Network. The PCIRN SOS Network was established in 2009 to prospectively monitor annual seasonal influenza vaccine effectiveness in the prevention of laboratory-confirmed influenza-related hospitalisation in Canadian adults using a test-negative case-control design.

In Canada, annual influenza vaccine is recommended for all persons aged six months to 59 months or 65 years and older, and for persons of any age with medical comorbidities placing them at higher risk of severe influenza and its complications resulting in hospitalisation or death [1]. More than $98 \%$ of influenza vaccine 
provided to adults is intramuscular split-virus trivalent inactivated influenza vaccine (TIV).

\section{Hospital-based surveillance}

The PCIRN SOS Network comprises 40 adult academic and community hospitals in seven of the 10 Canadian provinces and three territories (New Brunswick, Nova Scotia, Quebec, Ontario, Manitoba, Alberta and British Columbia), accounting for ca 18,000 adult acute care hospital beds. For the $2013 / 14$ season, beginning on 15 November 2013, trained SOS Network surveillance study staff (monitors) reviewed all daily admissions of people 16 years and older to medical and coronary ICU and medical wards (e.g. cardiology, respirology, family medicine, geriatric medicine, internal medicine) to identify eligible patients. Eligible patients were at least 16 years-old and admitted to participating hospitals with the following clinical presentations: pneumonia, acute exacerbation of chronic obstructive pulmonary disease or asthma, unexplained sepsis, any other respiratory infection or diagnosis, or any respiratory or influenza-like symptom (e.g. dypsnoea, cough, sore throat, myalgia, arthralgia, fever). One day per week, beginning when the local laboratory reported two or more positive influenza tests or when the local laboratory reported one or more positive influenza tests in two consecutive weeks, patients were screened who were admitted on that day with a triage temperature $\geq 37.5{ }^{\circ} \mathrm{C}$ associated with one of the following: acute coronary syndrome (e.g. myocardial infarction, unstable angina), any other cardiac diagnosis (e.g. atrial fibrillation, other arrhythmia, myocarditis), or stroke.
In hospitals associated with the Toronto Invasive Bacterial Diseases Network (TIBDN), influenza testing was performed seven days per week as routine clinical practice. A temperature cut-off of $\geq 37.5{ }^{\circ} \mathrm{C}$ was used in this subgroup of patients in order to attempt to minimise false-negative influenza PCR results associated with lag between influenza infection and related cardiac and stroke hospitalisations.

Nasopharyngeal swabs were collected from all eligible patients as part of routine clinical care or by the SOS Network monitor. The specimens were tested for influenza by reverse-transcriptase PCR (RT-PCR) or viral culture in the local hospital or public health laboratory according to routine local testing procedures. SOS Network monitors collected detailed demographic information, medical and surgical history, details of presenting illness, hospitalisation details including management and healthcare utilisation, discharge and 30-day post-discharge outcomes. The 2013/14 influenza immunisation history was collected from the patient or their caregiver and, if possible, verified with their immunisation provider or an immunisation registry. Patients were considered immunised if they reported receipt of a current-season influenza vaccine more than two weeks before onset of their symptoms. Only the subset of severe, life-threatening influenza requiring ICU admission, mechanical ventilation or causing death is described here in detail.

The study was approved by the Research Ethics Boards of participating institutions and consent procedures

\section{FIGURE}

Laboratory-confirmed influenza cases and test-negative controls admitted to PCIRN SOS Network hospitals by week and virus subtype, 15 November 2013-8 February $2014(n=1,844)$

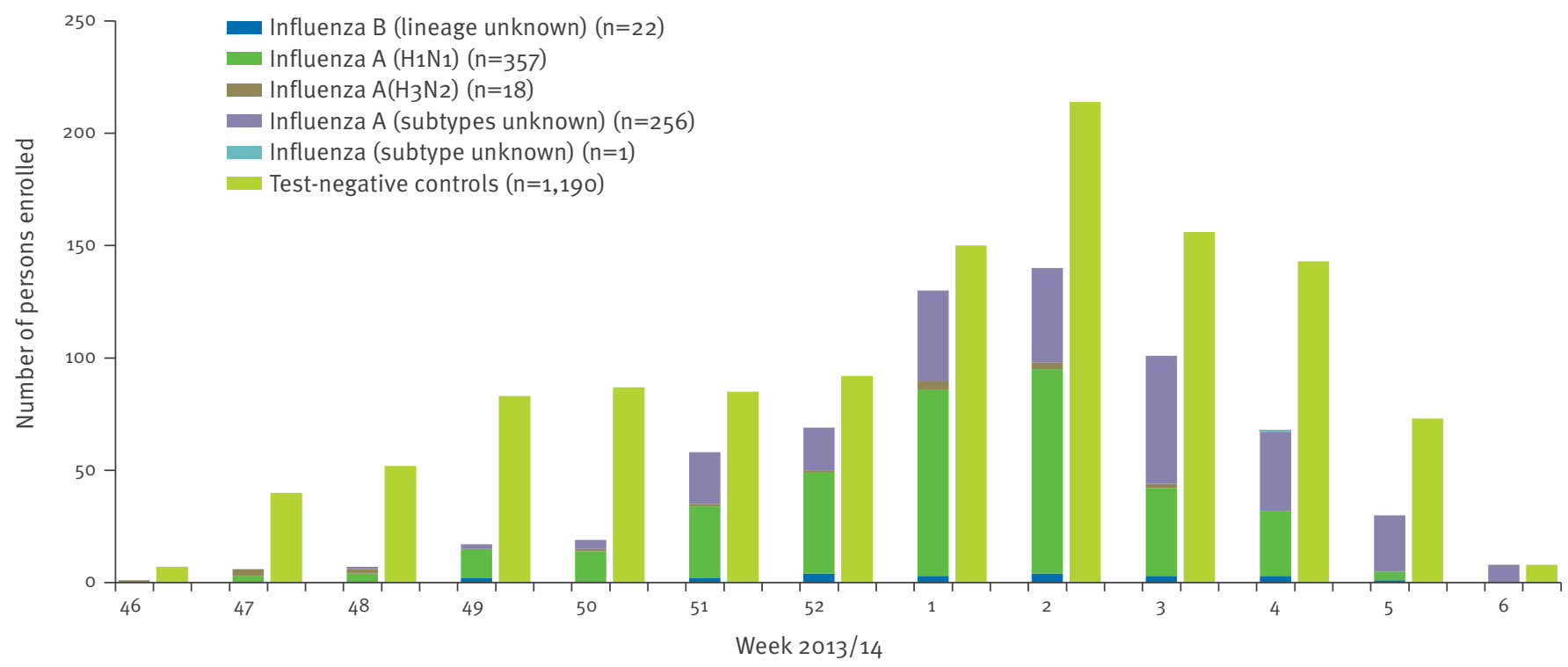


Clinical and demographic characteristics of laboratory-confirmed influenza cases and test-negative controls, Canada, 15 November 2013-8 February $2014(\mathrm{n}=1,844)$

\begin{tabular}{|c|c|c|c|c|}
\hline Characteristics & $\begin{array}{c}\text { Cases }(\mathrm{N}=654) \\
\mathrm{n}(\%)\end{array}$ & $\begin{array}{c}\text { Controls }(N=1,190) \\
n(\%)\end{array}$ & $\begin{array}{c}\text { Total }(\mathrm{N}=1,844) \\
\mathrm{n}(\%)\end{array}$ & $p$ value $^{a}$ \\
\hline $\begin{array}{c}\text { Mean age (range) } \\
16-49 \text { years } \\
50-64 \text { years } \\
65-75 \text { years } \\
>75 \text { years }\end{array}$ & $\begin{array}{c}58.5(16-98) \\
187(28.6) \\
219(33.5) \\
123(18.8) \\
125(19.1)\end{array}$ & $\begin{array}{c}67.9(17-104) \\
162(13.6) \\
282(23.7) \\
287(24.1) \\
459(38.6)\end{array}$ & $\begin{array}{c}64.6(16-104) \\
349(18.9) \\
501(27.2) \\
410(22.2) \\
584(31.7)\end{array}$ & $\begin{array}{c}0.00 \\
0.00 \\
- \\
- \\
-\end{array}$ \\
\hline Female & $334(51.1)$ & $608(51.1)$ & $942(51.1)$ & 1.00 \\
\hline $\begin{array}{l}\text { Inclusion criteria at enrollment } \\
\text { Pneumonia } \\
\text { Acute exacerbation of COPD or } \\
\text { asthma } \\
\text { Unexplained sepsis } \\
\text { Any other acute respiratory illness } \\
\text { Acute coronary syndrome } \\
\text { Any other cardiac diagnosis } \\
\text { Stroke } \\
\text { c,d }\end{array}$ & $\begin{array}{c}186(28.4) \\
131(20.0) \\
16(2.4) \\
414(63.3) \\
1(0.2) \\
4(0.6) \\
0(0)\end{array}$ & $\begin{array}{c}524(44.0) \\
283(23.8) \\
49(4.1) \\
521(43.8) \\
4(0.3) \\
4(0.3) \\
1(0.1)\end{array}$ & $\begin{array}{c}710(38.5) \\
414(22.5) \\
\\
65(3.5) \\
935(50.7) \\
5(0.3) \\
8(0.4) \\
1(0.1)\end{array}$ & $\begin{array}{l}0.00 \\
0.07 \\
0.07 \\
0.00 \\
0.66 \\
0.47 \\
1.00\end{array}$ \\
\hline One or more comorbidities & $257 / 290(88.6)$ & $351 / 370(94.9)$ & $608 / 660(92.1)$ & 0.004 \\
\hline Received 2013/14 influenza vaccine & $227(34.7)$ & $733(61.6)$ & $960(52.1)$ & 0.000 \\
\hline
\end{tabular}

COPD: Chronic obstructive pulmonary disease.

a Cases versus controls.

b Includes those with any other respiratory infection or diagnosis or any respiratory or influenza-like symptom (e.g. dypsnoea, cough, sore throat, myalgia, arthralgia, fever).

Includes only patients with a documented temperature of $\geq 37.5{ }^{\circ} \mathrm{C}$ at triage in the Emergency Department.

d Surveillance for acute coronary syndrome, other cardiac diagnoses and stoke was performed in SOS Network Sites outside of the Greater Toronto, Ontario sites only one day per week once influenza was known to be circulating locally.

followed local research ethics board requirements (clinical trial resgistration number: NCTo1517191).

\section{Estimation of influenza vaccine effectiveness}

All eligible patients hospitalised between 15 November 2013 and 8 February 2014 who underwent influenza testing and whose self-reported 2013/14 influenza immunisation status was available, were included in this interim analysis of vaccine effectiveness (VE). Hospitalised patients with a positive laboratory-test for influenza were defined as cases and those testing negative for influenza within seven days of onset of illness were defined as controls. Odds ratios (OR) for influenza vaccination among cases and controls were calculated and VE was estimated as (1-OR) x $100 \%$ by logistic regression adjusting for age and presence of one or more comorbidities. Overall adjusted VE and VE stratified by age (patients 65 years or older vs patients younger than 65 years) are presented.

\section{Interim estimates of influenza vaccine effectiveness}

A total of 654 hospitalised influenza cases and 1,190 hospitalised test-negative controls were enrolled between 15 November 2013 and 8 February 2014 and included in the interim analysis. Weekly incidence of laboratory-confirmed influenza among adults hospitalised in SOS Network sites by subtype is shown in the Figure. Overall, 631 of 654 (96.5\%) of admissions were due to influenza $A$; of those with a known subtype, influenza $A\left(\mathrm{H}_{1} \mathrm{~N}_{1}\right)$ accounted for 357 of 375 (95.2\%).

The mean age of patients admitted with laboratoryconfirmed influenza and of test-negative controls was 58.5 years (range: $16-98$ years) and 67.9 years (17-104 years), respectively; 406 of 654 cases (62.1\%) and 444 of 1,190 test-negative controls (37.3\%) were under 65 years of age, and $51.1 \%$ in both groups were female (Table 1). Among those for whom a medical history was available, $88.6 \%$ of cases and $94.9 \%$ of test-negative controls had one or more medical comorbidities predisposing to complications of influenza. Some $34.7 \%$ of cases and $61.6 \%$ of test-negative controls reported receipt of the 2013/14 influenza vaccine.

The overall and age-stratified VE for the prevention of laboratory-confirmed influenza-related hospitalisation in Canadian adults are shown in Table 2. Overall interim VE of 2013/14 influenza vaccines in persons 16 years and older, adjusted for age and the presence of one or more medical comorbidities, was $58.5 \%$ (90\% $\mathrm{Cl}$ : 43.9-69.3). Among adults 65 years and older, the interim adjusted VE was $58.1 \%$ (90\% Cl: $35.4-72.8)$ and among adults under 65 years of age, the interim adjusted VE was $60.3 \%$ (90\% Cl: 39.4-74.0). Overall adjusted VE against confirmed influenza $A\left(\mathrm{H}_{1} \mathrm{~N}_{1}\right)$ was $57.9 \%$ (90\% Cl: 37.7-71.5). 
Clinical and epidemiological characteristics of patients with severe laboratoryconfirmed influenza

Overall, $20.6 \%$ of the 654 hospitalised influenza cases admitted to SOS Network hospitals were severe, defined as requiring ICU admission, mechanical ventilation, or resulting in death. The mean age of severe cases was 58.6 years (22-98 years); $68.1 \%$ of severe cases were younger than 65 years (Table 3 ). Of the severe cases with available medical records, $84.7 \%$ had one or more comorbidities associated with increased risk of influenza complications. Of the severe cases, $33.9 \%$ reported receipt of the 2013/14 influenza vaccine $(39.0 \%$ of cases with underlying comorbidity vs $5.3 \%$ of cases with no comorbidity; $p=0.003$ ). Until 8 February 2014, the overall mortality among hospitalised cases has been $4.9 \%$, and of 32 deaths, 18 occurred in patients under the age of 65 years.

\section{Discussion}

The 2013/14 influenza season in Canada has been dominated by influenza $A\left(\mathrm{H}_{1} \mathrm{~N}_{1}\right)$ pdmog virus. Current data suggest that the virus circulating in Canada is well matched to the recommended vaccine strain; $84 \%$ of strains tested were $\mathrm{A} / \mathrm{California/07/2009-like} \mathrm{influ-}$ enza $A\left(\mathrm{H}_{1} \mathrm{~N}_{1}\right)$ [2]. Our interim VE estimates confirm moderate but clinically and statistically significant protection against serious influenza outcomes of clinical and public health importance. Our findings further suggest important potential changes in the epidemiology of severe, hospitalised influenza $A\left(\mathrm{H}_{1} \mathrm{~N}_{1}\right)$ compared with the 2009 pandemic, including an increase in the median age and the proportion of patients with comorbidity [3]. Furthermore, while overall mortality was $4.9 \%$, similar to that observed during the 2009 influenza $A\left(\mathrm{H}_{1} \mathrm{~N}_{1}\right)$ pandemic [3], seasonal circulation of influenza $A\left(\mathrm{H}_{1} \mathrm{~N}_{1}\right)$ in $2013 / 14$ was associated with need for admission to an ICU in 19\% (90\% Cl:16.5-21.7\%) of adults hospitalised in SOS Network hospitals compared with $29 \%$ during the pandemic, suggesting a shift in the epidemiology of influenza $A\left(\mathrm{H}_{1} \mathrm{~N}_{1}\right)$ to less severe disease more typical of seasonal influenza outbreaks. ICU admission was required in $12.7 \%(90 \% \mathrm{Cl}$ 10.5-15.1\%) during the influenza B-dominated 2011/12 season and $14.9 \%(13.3-16.6 \%)$ during the influenza $A\left(\mathrm{H}_{3} \mathrm{~N}_{2}\right)$-dominated $2012 / 13$ season (PCIRN SOS Network, unpublished data).

Rates of ICU admission among patients admitted to hospital with laboratory-confirmed influenza during the pandemic are readily available from many countries and range from a low of $10 \%$ in the United Kingdom and the Netherlands to highs of $25 \%$ to $30 \%$ in the United States (US) [4-8]. Fewer studies report rates of ICU admission among patients admitted with laboratoryconfirmed seasonal influenza, and rates vary widely by season and virus type/subtype [9-12]. Over three influenza seasons (2005-08) in the US, $14 \%$ of hospitalised influenza cases required ICU admission while in the 2010/11 season, ICU admission was required for $25.5 \%$ of influenza $A\left(\mathrm{H}_{1} \mathrm{~N}_{1}\right), 13.5 \%$ of $A\left(\mathrm{H}_{3} \mathrm{~N}_{2}\right)$ and $15.9 \%$ of
TABLE 2

Interim assessment of 2013/14 influenza vaccine effectiveness in the prevention of laboratory-confirmed influenza-related hospitalisation in adults, Canada, 15 November 2013-8 February $2014(n=1,844)$

\begin{tabular}{|c|c|c|}
\hline & $\begin{array}{c}\text { Vaccine } \\
\text { effectiveness } \\
\text { estimate (\%) }\end{array}$ & $\begin{array}{c}90 \% \text { confidence } \\
\text { interval }\end{array}$ \\
\hline \multicolumn{3}{|l|}{ Unadjusted } \\
\hline $\begin{array}{l}\text { All influenza strains } \\
\text { Overall } \\
\text { Age } \geq 65 \text { years } \\
\text { Age } 665 \text { years }\end{array}$ & $\begin{array}{l}66.9 \\
59.4 \\
57.3 \\
\end{array}$ & $\begin{array}{c}60.8-72.0 \\
47.9,-68.3 \\
45.2-66.6 \\
\end{array}$ \\
\hline $\begin{array}{l}\text { Confirmed influenza } A\left(\mathrm{H}_{1} \mathrm{~N}_{1}\right) \\
\text { Overall } \\
\text { Age } \geq 65 \text { years } \\
\text { Age }<65 \text { years }\end{array}$ & $\begin{array}{l}66.8 \\
57.4 \\
59.7\end{array}$ & $\begin{array}{l}59.2-73.0 \\
41.8-68.8 \\
45.2-70.4 \\
\end{array}$ \\
\hline \multicolumn{3}{|l|}{ Adjusted $^{a}$} \\
\hline $\begin{array}{l}\text { All influenza strains } \\
\text { Overall } \\
\text { Age } \geq 65 \text { years } \\
\text { Age } 665 \text { years } \\
\end{array}$ & $\begin{array}{l}58.5 \\
58.1 \\
60.3 \\
\end{array}$ & $\begin{array}{l}43.9-69.3 \\
35.4-72.8 \\
39.4-74.0\end{array}$ \\
\hline $\begin{array}{l}\text { Confirmed influenza } A\left(\mathrm{H}_{1} \mathrm{~N}_{1}\right) \\
\text { Overall } \\
\text { Age } \geq 65 \text { years } \\
\text { Age }<65 \text { years }\end{array}$ & $\begin{array}{l}57.9 \\
63.1 \\
54.2 \\
\end{array}$ & $\begin{array}{l}37.7-71.5 \\
34.7-79.1 \\
21.6-73.2 \\
\end{array}$ \\
\hline
\end{tabular}

adjusted for age and presence of one or more comorbidities.

influenza $B$ cases in the US and $27 \%$ of influenza $A$ and $15 \%$ of influenza B hospitalisations in Australia [9-11]. In Spain, $24.4 \%$ of hospitalised patients with influenza in 2010/11 required admission to ICU [12].

The majority of patients requiring admission to an $\mathrm{ICU}$, requiring mechanical ventilation or who died in SOS Network hospitals during the 2013/14 season had underlying medical comorbidities known to increase the risk of influenza complications and making them eligible for free influenza vaccine. Despite this, vaccine coverage in this high-risk group was only $39 \%$; of those with severe disease, only $33 \%$ overall and $21.7 \%$ of those under 65 years of age had been vaccinated.

Our interim adjusted point estimate for VE against laboratory-confirmed influenza-related hospitalisation of $58.5 \%(90 \% \mathrm{Cl}: 43.9-69.3)$ is similar to that reported in the United States (61\%; $95 \% \mathrm{Cl}: 52-68)$ [13] but lower than that reported by the outpatient sentinel surveillance network for prevention of medically attended laboratory-confirmed influenza (74\%; $95 \% \mathrm{Cl}$ : 58-83) [14]. This is not surprising given that the population captured by the outpatient sentinel surveillance network is dominated by healthy working -age adults with comparatively few underlying medical comorbidities while the PCIRN SOS Network assesses VE in a cohort of hospitalised patients who were older (median age: 65 vs 37 years) and much more likely to have underlying medical comorbidities (92 vs $22 \%$ ) [14,15]. Although lower than that observed for medically attended influenza in the community, effectiveness of the 2013/14 
seasonal influenza vaccines in the prevention of serious, clinically important outcomes in adults of all ages was substantial, with reduction of influenza-associated hospitalisations of approximately $55-60 \%$. As of 5 March 2014, the only other published study to report interim estimates of 2013/14 influenza VE against laboratory-confirmed hospitalisation is from Navarre, Spain, and reported lower overall and $\mathrm{A}\left(\mathrm{H}_{1} \mathrm{~N}_{1}\right)$ specific VE [16]. However, potential differences in health systems, health seeking behaviour, number of cases and patterns of virus circulation $\left(60 \% \mathrm{~A}_{3}\left(\mathrm{H}_{3} \mathrm{~N}_{2}\right)\right.$ and $40 \%$ $A\left(H_{1} N_{1}\right)$ in the Navarre study) preclude a meaningful comparison with the present study.

Our findings are subject to at least two limitations. Firstly, as with other observational assessments of influenza vaccine effectiveness, the existence of bias and residual confounding cannot be excluded. We employed the test-negative case-control design, the currently preferred observational approach to assessing influenza vaccine effectiveness, to minimise misclassification and indication bias [17]. Secondly, while we are collecting data on numerous covariates in an attempt to adjust for potential confounders, these data were unavailable for the interim analysis. Consequently, the end-of-season, fully adjusted, VE estimates may be different. Although this has not been the experience of the Canadian outpatient sentinel surveillance network for the 2012/13 influenza season, the I-MOVE network in Europe reported important, but not statistically significant, differences between mid-season and end-ofseason VE estimates $[14,18]$.

Our findings highlight that important public health benefits of influenza vaccination are lost to poor immunisation coverage rates in some at-risk populations. Targeted public health messaging is important to encourage adults of all ages with medical comorbidity to seek annual influenza vaccination. The 2013/14 season has been unique in that it is the first predominant influenza $A\left(\mathrm{H}_{1} \mathrm{~N}_{1}\right)$ season since the 2009 pandemic, allowing us to characterise potential changes in the epidemiology and clinical severity of influenza $A\left(\mathrm{H}_{1} \mathrm{~N}_{1}\right)$ pdmog as it becomes a seasonal virus. These data are important to guide public health risk communication and inform immunisation, prevention, and treatment recommendations for the 2014/15 season, which are currently being developed by National Immunization Technical Advisory Groups (NITAGS) in many countries around the world, including the Canadian National Advisory Committee on Immunization (NACl).

While the demonstrated effectiveness of $58 \%$ against serious disease due to influenza is modest, it arguably represents a significant clinical, public health and health service/cost benefit, given the burden of severe disease resulting in hospitalisation and its downstream complications including ICU admission, pneumonia, disability and death. While our data for the current vaccine suggests prevention of almost $60 \%$ of influenza hospitalisations with vaccination in
TABLE 3

Clinical and demographic characteristics of severe laboratory-confirmed influenza resulting in admission to an intensive care unit, mechanical ventilation or death, Canada, 15 November 2013-8 February $2014(n=135)$

\begin{tabular}{|l|c|}
\hline Characteristic & $\begin{array}{c}\text { Death, ICU or } \\
\text { mechanical } \\
\text { ventilation }(\mathrm{N}=135) \\
\mathrm{n}(\%)\end{array}$ \\
\hline Mean age (range) & $58.6(22-98)$ \\
$16-49$ years & $35(25.9)$ \\
$50-64$ years & $57(42.2)$ \\
$65-75$ years & $24(17.8)$ \\
'75 years & $19(14.1)$ \\
\hline Female & $61(45.2)$ \\
\hline Received 2013/14 influenza vaccine & \\
Overall & $45(33.3)$ \\
$16-49$ years & $2(5.7)$ \\
$50-64$ years & $18(31.6)$ \\
$65-75$ years & $13(54.2)$ \\
I75 years & $12(63.2)$ \\
\hline Influenza type & \\
Influenza A & $131(97.0)$ \\
A(H1N1) & $84(62.2)$ \\
A(H3N2) & $3(2.2)$ \\
A (subtype unknown) & $44(32.6)$ \\
Influenza B & $4(3.0)$ \\
\hline One or more comorbidity & \\
Yes & \\
Diabetes (no end-organ complications) & $105 / 124(84.7)$ \\
Diabetes with complications & $33 / 124(26.6)$ \\
Cardiac disease & $8 / 124(6.5)$ \\
Pulmonary disease & $39 / 118(33.1)$ \\
Asthma & $50 / 124(40.3)$ \\
COPD & $13 / 124(10.5)$ \\
Renal disease & $28 / 124(22.6)$ \\
Neuromuscular disease & $14 / 121(11.6)$ \\
Cancer & $16 / 121(13.2)$ \\
No & $20 / 121(16.5)$ \\
Unknown & $19 / 124(15.3)$ \\
\hline Deaths & $11 / 135(8.1)$ \\
Mean age (range) & $32 / 654(4.9)$ \\
$16-49$ years & $64.8(28-98)$ \\
$50-64$ years & $6(18.8)$ \\
$65-75$ years & $12(37.5)$ \\
$\geq 75$ years & $5(15.6)$ \\
\hline & $9(28.1)$ \\
\hline
\end{tabular}

COPD: Chronic obstructive pulmonary disease; ICU: intensive care unit.

a Comorbidities reported as rates among those with available data; denominator represents number of patients in whom this data point was available.

a well matched influenza $A\left(\mathrm{H}_{1} \mathrm{~N}_{1}\right)$-dominated season affecting predominantly younger adults with comorbidity, the unchanged vaccine recommended by the World Health Organization for the 2014/15 season may have very different effectiveness (better or worse) in the coming season depending on circulating strains and vaccine match. While an anticipated VE of $58 \%$ against hospitalisation is reasonable given the effectiveness observed in 2013/14, ongoing surveillance and mid-season estimates during the coming season will be critical to ensure that the vaccine is performing as anticipated and to provide early signal of possible drift, should the VE be lower than anticipated. 


\section{Acknowledgments}

This study was funded by the Canadian Institutes of Health Research (Grant \#124309) and through a Collaborative Research Agreement with GlaxoSmithKline Biologicals SA. The authors wish to thank the dedicated SOS Network Surveillance monitors whose tremendous efforts make this study possible.

\section{Conflict of interest}

VS, FH and BI are employed by the GlaxoSmithKline Group of Companies. VS reports ownership of stock options and/or restricted shares in the GlaxoSmithKline Group of Companies; SAM research grants from GlaxoSmithKline, Pfizer, Sanofi Pasteur; JML research grants from GlaxoSmithKline and Sanofi Pasteur and other from AstraZeneca; JM personal fees from GlaxoSmithKline, Medimmune, Merck, Sanofi Pasteur; JP GlaxoSmithKline, Pfizer and personal fees from Merck and Pfizer; LV research grants from GlaxoSmithKline, Pfizer, Optimer, Cubist and Merck, and personal fees from Merck, Optimer and Cubist. This study is funded by the Public Health Agency of Canada, the Canadian Institutes of Health Research, and through a Collaborative Research Agreement with GlaxoSmithKline Biologicals SA.

\section{Authors' contributions}

SAM, VS, MA, AA, TFH, FH, DMC, LY, AM were involved in the conception and design of the study; SAM, GB, WB, FDM, KG, SH, KK, JML, PLW, BL, ML, JM, AEM, AP, JP, DR, MS, SS, DS, GS, ST, LV, DW, and AM were responsible for acquisition of data; TFH, JL, ME conducted/supervised the PCIRN SOS Network central laboratory; SAM, VS, FH, DMC, AM, LY analysed and interpreted the data; SAM drafted the manuscript; all authors revised the manuscript critically for important intellectual content; all authors reviewed and approved the final draft of the manuscript.

\section{References}

1. National Advisory Committee on Immunization. Statement on Seasonal Influenza Vaccine for 2013-2014. Canada communicable disease report. 2013;39(ACS-4):1-37. Available from: http://www.phac-aspc.gc.ca/publicat/ccdr-rmtc/13vol39/ acs-dcc-4/index-eng.php

2. Public Health Agency of Canada. FluWatch report: February 2 to 8, 2014 (Week 06) FluWatch 2014:6. Available from: http:// www.phac-aspc.gc.ca/fluwatch/13-14/wo6_14/index-eng.php

3. Helferty M, Vachon J, Tarasuk J, Rodin R, Spika J, Pelletier L. Incidence of hospital admissions and severe outcomes during the first and second waves of pandemic ( $\left.\mathrm{H}_{1} \mathrm{~N}_{1}\right)$ 2009. CMAJ. 2010;182(18):1981-7. http://dx.doi.org/10.1503/cmaj.100746

4. van 't Klooster TM, Wielders CC, Donker T, Isken L, Meijer A, van den Wijngaard CC, et al. Surveillance of Hospitalisations for 2009 Pandemic Influenza $A\left(\mathrm{H}_{1} \mathrm{~N}_{1}\right)$ in the Netherlands, 5 June - 31 December 2009. Euro Surveill. 2010;15(2):pii=19461.

5. Campbell CN, Mytton OT, McLean EM, Rutter PD, Peabody RG, Sachedina N, et al. Hospitalisation in two waves of pandemic influenza $A\left(\mathrm{H}_{1} \mathrm{~N}_{1}\right)$ in England. Epidemiol Infect. 2011;139(10):1560-9.

http://dx.doi.org/10.1017/S0950268810002657

6. Bandaranayake D, Jacobs M, Baker M, Hunt D, Wood T, Bissielo A, et al. The second wave of 2009 pandemic influenza $A\left(\mathrm{H}_{1} \mathrm{~N}_{1}\right)$ in New Zealand, January-October 2010. Euro Surveill. 2011;16(6): pii=19788.

7. Jain S, Kamimoto L, Bramley AM, Schmitz AM, Benoit SR, Louie J, et al. Hospitalized patients with $2009 \mathrm{H}_{1} \mathrm{~N}_{1}$ influenza in the United States, April - June 2009. N Engl J Med. 2009;361(20):1935-44. http://dx.doi.org/10.1056/NEJMoaogo6695

8. Bramley, Dasgupta S, Skarbinski J, Kamimoto L, Fry AM, Finelli $\mathrm{L}$, et al. Intensive care unit patients with 2009 pandemic influenza A (H1N1pdmo9) virus infection - United States, 2009.
Influenza Other Respir Viruses. 2012;6(6):e134-42. http://dx.doi.org/10.1111/j.1750-2659.2012.00385.x

9. Dao CN, Kamimoto L, Nowell M, Reingold A, Gershman K, Meek J, et al. Adult hospitalizations for laboratory-positive influenza during the 2005-2006 through 2007-2008 seasons in the United States. J Infect Dis. 2010;202(6):881-8. http://dx.doi.org/10.1086/655904

10. Chaves SS, Aragon D, Bennett N, Cooper T, D'Mello T, Farley $M$, et al. Patients hospitalized with laboratory-confirmed influenza during the 2010-2011 influenza season: Exploring disease severity by virus type and subtype. J Infect Dis. 2013;208(8):1305-14 http://dx.doi.org/10.1093/infdis/jit316

11. Cheng AC, Holmes M, Irving LB, Brown SG, Waterer GW, Korman TM, et al. Influenza vaccine effectiveness against hospitalisation with confirmed influenza in the 2010-11 seasons: a test-negative observational study. PloS One. 2013;8(7):e6876o. http://dx.doi.org/10.1371/journal.pone.0068760

12. Delgado-Rodriguez M, Castilla J, Godoy P, Martin V, Soldevila $\mathrm{N}$, Alonso J, et al. Different prognosis in hospitalized patients with influenza one season after the pandemic $\mathrm{H}_{1} \mathrm{~N}_{1}$ influenza of 2009-2010 in Spain. Influenza Other Respir Viruses. 2013;7(6):1336-42. http://dx.doi.org/10.1111/irv.12119

13. Flannery B, Thaker SN, Clippard J, Monto AS, Ohmit SE, Zimmerman RK, et al. Interim estimates of 2013-14 seasonal influenza vaccine effectiveness - United States, february 2014. MMWR Morb Mortal Wkly Rep. 2014;63(7):137-42.

14. Skowronski D, Chambers C, Sabaiduc S, De Serres G, Dickinson J, Winter A, et al. Interim estimates of 2013/14 vaccine effectiveness against influenza $A\left(\mathrm{H}_{1} \mathrm{~N}_{1}\right)$ pdmo9 from Canada s sentinel surveillance network, January 2014. Euro Surveill. 2014;19(5): pii=20690. http://dx.doi.org/10.2807/1560-7917.ES2014.19.5.20690

15. Skowronski DM, Janjua NZ, Sabaiduc S, De Serres G, Winter $A L$, Gubbay JB, et al. Influenza A/subtype and B/lineage effectiveness estimates for the 2011-12 trivalent vaccine: cross-season and cross-lineage protection with unchanged vaccine. J Infect Dis. 2014; Jan 19. [Epub ahead of print]. http://dx.doi.org/10.1093/infdis/jiu048

16. Castilla J, Martínez-Baz I, Navascués A, Fernandez-Alonso M, Reina G, Guevara M, et al. Vaccine effectiveness in preventing laboratory-confirmed influenza in Navarre, Spain: 2013/14 midseason analysis. Euro Surveill. 2014;19(6): pii=20700. http://dx.doi.org/10.2807/1560-7917.ES2014.19.6.20700

17. Jackson ML, Nelson JC. The test-negative design for estimating influenza vaccine effectiveness. Vaccine. 2013;31(17):2165-8. http://dx.doi.org/10.1016/j.vaccine.2013.02.053

18. Kissling E, Valenciano M, Buchholz U, Larrauri A, Cohen JM, Nunes B, et al. Influenza vaccine effectiveness estimates in Europe in a season with three influenza type/subtypes circulating: the I-MOVE multicentre case-control study, influenza season 2012/13. Euro Surveill. 2014;19(6): pii=20701. http://dx.doi.org/10.2807/1560-7917.ES2014.19.6.20701 